\title{
Odontogenic Keratocyst finding with Cone Beam Computed Tomography (CBCT): a case report
}

\author{
Phimatra Jaya Putra ${ }^{1 *}$, Hutomo Mandala Hartoyo ${ }^{2}$, Mellisa Sim ${ }^{3}$
}

\begin{abstract}
Objectives: The purpose of this case report is to treatment plan is to remove the lesion and perform analyze the incidental finding of an odontogenic a biopsy and perform postoperative panoramic keratocyst on cone beam computed tomography radiograph. (CBCT) examination for the case of an impacted tooth 48.

Conclusion: The characteristics of the odontogenic keratocyst lesion can be visualized clearly on CBCT. Case Report: A 48-year-old man came with a consul The use of CBCT in analyzing the type and size of letter to perform a CBCT examination with the lesion is very helpful in planning surgical complaints of loose teeth on the right posterior treatment. Odontogenic keratocysts can be wellmandible starting from the premolars. diagnosed using a combination of CBCT Coincidentally found on a sagittal view showed a examination with histopathological examination to wide radiolucency lesion on the internal part of the determine the most effective management and jaw and not related to the impacted tooth. The prevent a recurrence.

${ }^{1}$ Department of Oral and Maxillofacial Radiology, Faculty of Dentistry, Universitas Prima Indonesia, Medan, Indonesia 20118

${ }^{2}$ Private Clinic, Bandung, Indonesia

${ }^{3}$ Department of Biomedics, Faculty of Dentistry, Universitas Prima Indonesia, Medan, Indonesia 20118

\section{*Correspondence to:}

Phimatra Jaya Putra

$\otimes$ phimatrajayaputra@unprimdn.ac.id

Received on: May 2021 Revised on: July 2021

Accepted on: July 2021

Keywords: Cone beam computed tomography, odontogenic keratocyst

Cite this article: Putra PJ, Hartoyo HM, Sim M. Odontogenic Keratocyst finding with Cone Beam Computed Tomography (CBCT): a case report. Jurnal Radiologi Dentomaksilofasial Indonesia 2021;5(2)60-5. https://doi.org/10.32793/ jrdi.v5i2.705

\section{INTRODUCTION}

Odontogenic keratocyst (OKC) merupakan lesi intraosseous yang bersumber secara odontogenik dan dijelaskan pertama kali oleh Phillipsen pada tahun $1956 .^{1}$ Odontogenic keratocyst memiliki cir yang bersifat agresif dengan rekurensi yang cukup tinggi. ${ }^{2}$ World Health Organization (WHO) pada tahun 2015 mengklasifikasikan odontogenic keratocyst sebagai tumor dan mengubah namanya sebagai Keratocystic Odontogenic Tumor (KCOT), hal ini berdasarkan pada perilaku odontogenic keratocyst yang menyerupai neoplasma dan tidak seperti kista, sehingga pada klasifikasi WHO terbaru yang diterbitkan pada tahun 2017, istilah Odontogenic keratocyst digunakan kembali dan menggantikan istilah Keratocystic Odontogenic Tumor karena kurangnya bukti sebagai lesi kista yang berasal dari perilaku neoplastik. ${ }^{1,3}$ Odontogenic keratocyst dikenal juga sebagai kista dermoid, cholesteatoma, keratocystomia, dan kista primordial. ${ }^{4}$ Etiologi odontogenic keratocyst belum diketahui secara pasti namun kemungkinan berkaitan dengan dental lamina yang sedang berkembang maupun dari dental lamina yang masih tersisa setelah masa perkembangan gigi. ${ }^{4}$ Odontogenic keratocyst sedikit lebih umum ditemukan pada laki-laki dibandingkan dengan perempuan dan banyak terjadi pada rentang usia antara dekade kedua dan ketiga. ${ }^{5}$ Odontogenic keratocyst dapat terjadi pada seluruh bagian rahang, namun lebih umum terjadi pada bagian posterior dari badan mandibula dan ramus. ${ }^{6}$ Odontogenic keratocyst sering pula terjadi pada daerah bergigi (82\%) dan beberapa kasus berkaitan dengan satu gigi yang mengalami impaksi $(27 \%$ pada daerah molar ketiga mandibula). ${ }^{7}$ Pusat pertumbuhan odontogenic keratocyst berada di bagian superior hingga inferior dari kanalis saraf alveolar pada sisi kanan. Odontogenic keratocyst terkadang tidak menimbulkan gejala, namun pada beberapa kasus dapat terjadi peningkatan sensitivitas pada gigi maupun adanya pembengkakan kecil yang dapat terlihat secara visual, rasa sakit dapat muncul saat terjadi infeksi sekunder. ${ }^{1}$ Aspirasi pada daerah yang dicurigai dapat ditemukan bahan pekat, berwarna kekuningan, dan bertekstur seperti keju. ${ }^{7-9}$

Odontogenic keratocyst saat dilakukan pemeriksaan radiografi rutin. ${ }^{10}$ Tampilan odontogenic keratocyst pada pada radiograf memiliki batas kortikal, kecuali jika terjadi infeksi sekunder. ${ }^{11}$ Odontogenic keratocyst dapat berbentuk oval atau bulat, dengan tepi halus yang mirip seperti kebanyakan kista, maupun dapat berbatas scalloped. ${ }^{12}$ Pada struktur internal Odontogenic keratocyst didapat gambaran radiolusen meskipun terdapat keratin yang tidak 
meningkatkan radiopasitas. $^{9}$ Terdapat pula gambaran multilocular karena munculnya septa internal. ${ }^{13}$ Odontogenic keratocyst memiliki cir yang khas yaitu memiliki kecenderungan untuk tumbuh pada bagian internal rahang, sehingga terjadi perluasan minimal pada lempeng kortikal. ${ }^{14}$ Odontogenic keratocyst juga mengakibatkan resorpsi akar pada gigi yang terlibat, walaupun dengan derajat yang lebih kecil dibandingkan kista dentigerous. Diagnosis banding dari odontogenic keratocyst antara lain adalah ameloblastoma, kista periodontal, kista radicular, kista dentigerous, dan odontogenic myxoma. ${ }^{9,13}$

Tujuan penulisan laporan kasus ini adalah untuk mendeskripsikan temuan odontogenic keratocyst pada pemeriksaan Cone-Beam Computed Tomography (CBCT) untuk kasus gigi goyang tanpa diagnosis klinis serta dikonfimasi dengan pemeriksaan Histopatologis. Kasus yang dilaporkan dalam laporan kasus ini cukup jarang terjadi karena biasanya odotogenik keratocyst perlu pemeriksaan lebih lanjut untuk mendapatkan diagnosis yang lebih jelas.

\section{CASE REPORT}

Seorang pria berusia 46 tahun datang dengan keluhan gigi goyang pada bagian posterior bawah kanan mulai dari gigi 45 ke belakang. Pemeriksaan klinis adanya pembengkakan pada daerah tersebut, dengan hasil pemeriksaan tes dingin negative (-) dan tes panas negatif (-) serta adanya kegoyangan derajat 2 dari gigi premolar sampai geraham pada bagian bawah kanan. Terdapat juga gigi impaksi 48 pada bagian tersebut. Pasien dilakukan konsul untuk melakukan pemeriksaan radiografi Cone Beam Computed Tomography (CBCT) pada regio 4 tersebut. Diagnosis klinis pada pasien ini belum diketahui sebelum pemeriksaan karena tidak disebutkan dalam surat pengantar.

Hasil pemeriksaan CBCT tampak adanya gigi 48 (gigi molar tiga rahang bawah kanan) dengan posisi horizontal dan tidak dapat erupsi dengan sempurna karena tidak cukup ruangan dan posisi gigi yang tidur atau horizontal. Pada pandangan sagital tampak adanya lesi radiolusensi luas pada daerah regio 4 (inferior dextra). Tampak gambaran Multi Planar atau MPR (Multiplanar reformation or reconstruction) (Gambar 1) adanya kerusakan tulang yang luas.

Gambaran 3D lesi radiolusensi tampak tulang alveolar mandibula regio 4 tampak tembus dari kortikal bukal ke arah lingual dengan akar gigi 45-47 masih tampak jelas (panah hijau), tampak juga adanya gigi Impaksi 48 horizontal terbenam (panah ungu). Tampak batas kortikal tulang bukal lingual telah menghilang serta adanya ekspansi ke arah inferior dari batas tulang kortikal mandibula yang masih intact atau masih tersambung (panah biru).

Pada pandangan sagital tampak lesi meluas mulai dari distal gigi 44 sampai ke arah distal gigi 47. Akar gigi yang terlibat tidak tampak adanya resorpsi. Pemeriksaan CBCT mendapatkan ukuran luas lesi dari potongan sagital sekitar $32,55 \mathrm{~mm} x$ $35,78 \mathrm{~mm}$ (Gambar 2). Lesi radiolusensi tidak

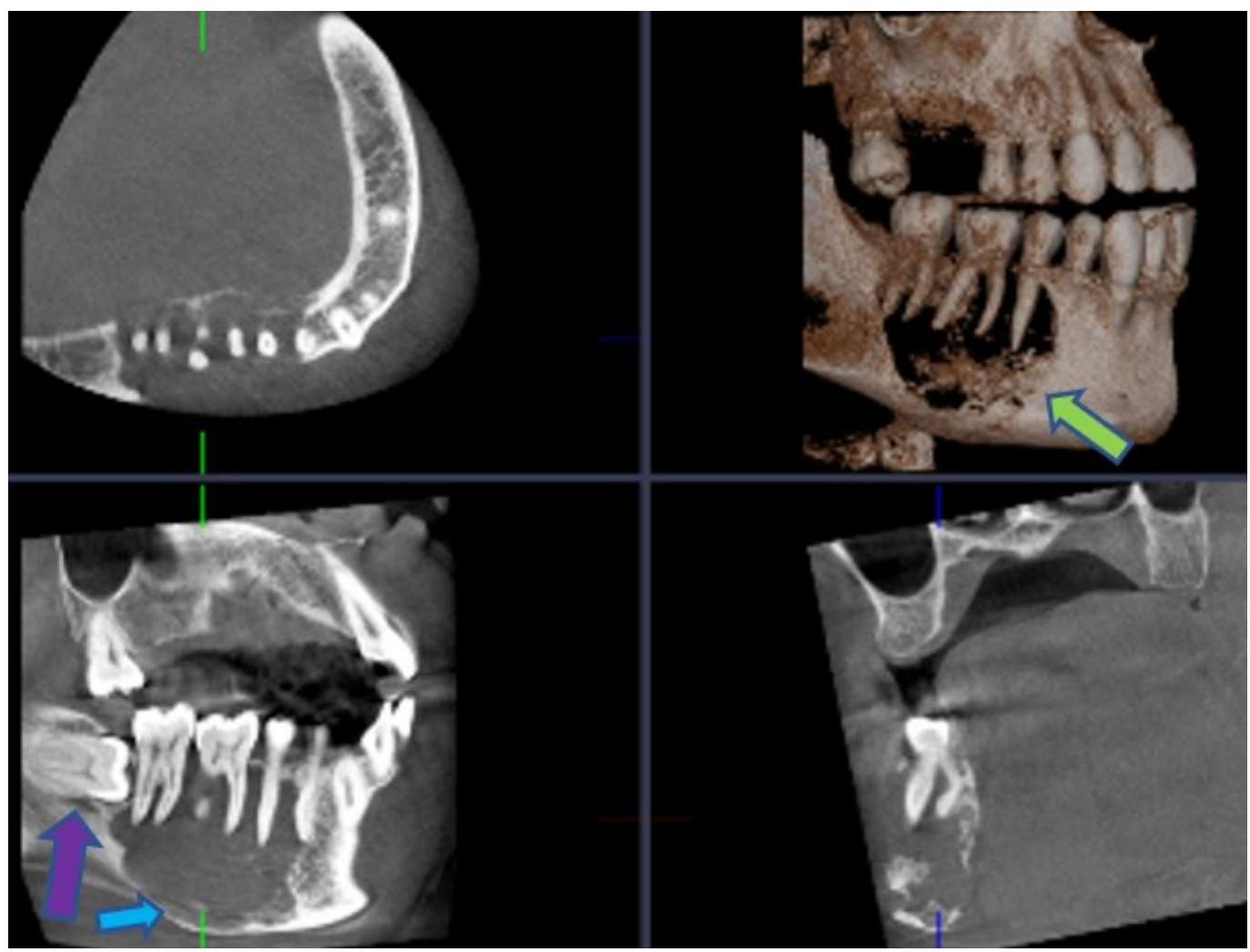

Gambar 1. Tampilan MPR (Multiplanar reformation) dari regio 4 (madibula dextra) pada pemeriksaan radiografi CBCT 


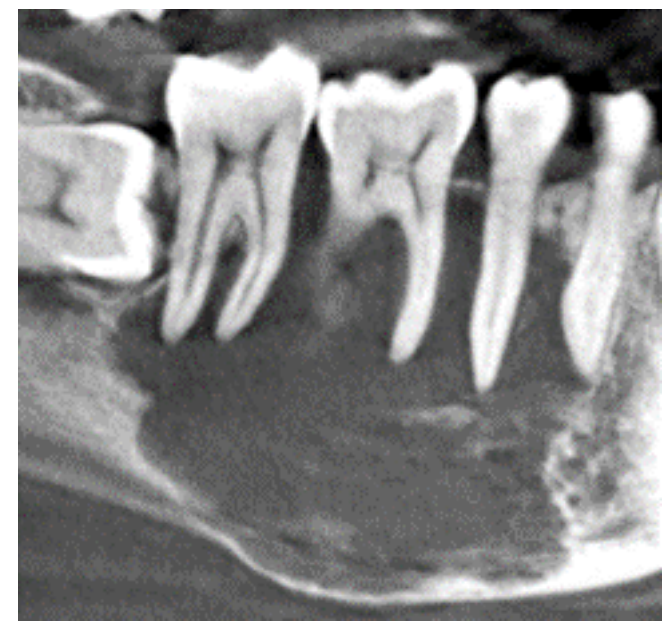

Gambar 2. Potongan sagittal lesi radiolusensi regio 4

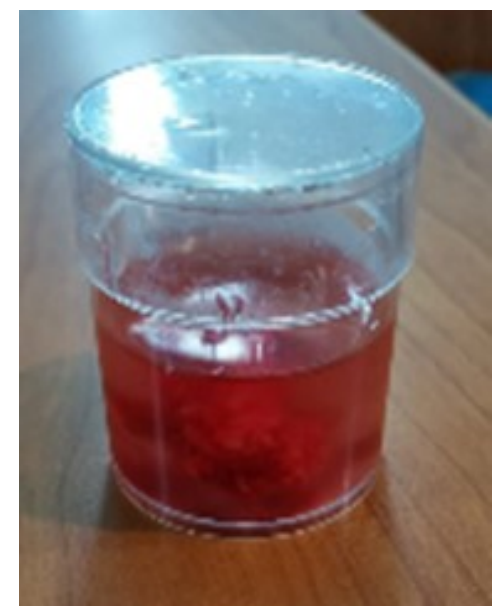

Gambar 3. Sediaan untuk dilakukan pemeriksaan biopsi

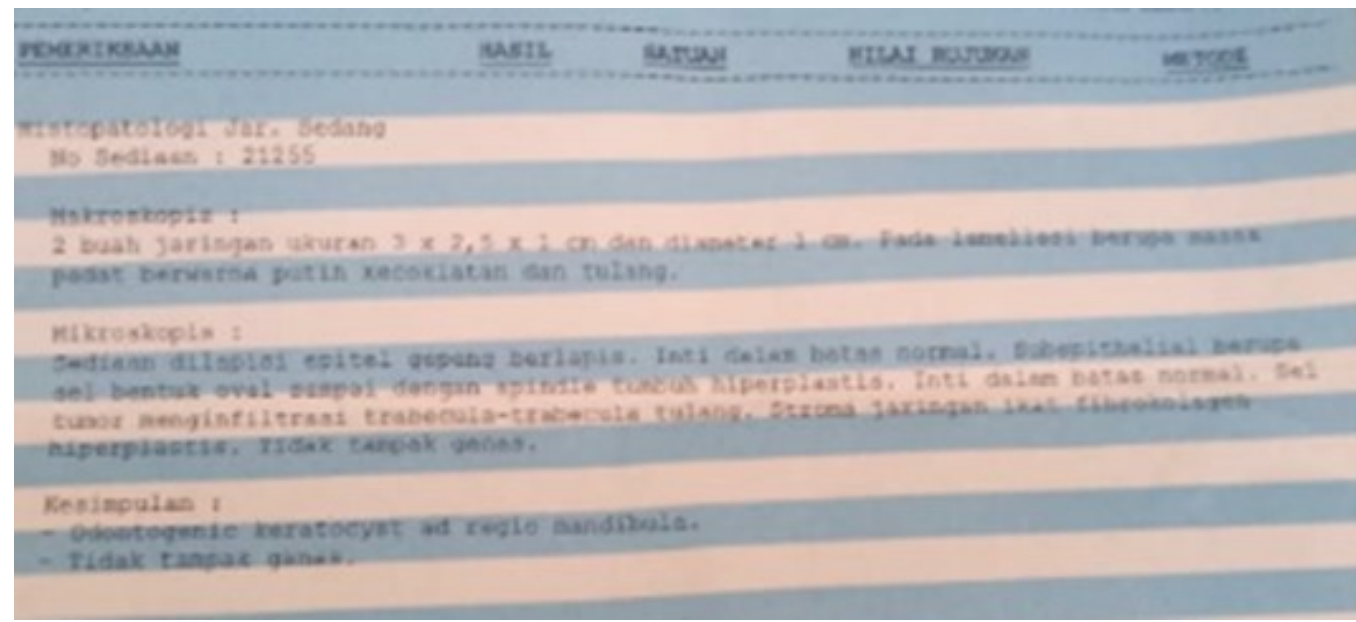

Gambar 4. Lembar hasil pemeriksaan histopatologis

tampak berhubungan dengan gigi impaksi 48 dengan masih tampak kortikasi tulang sekitar mahkota gigi 48.

Pemeriksaan interpretasi $\mathrm{CBCT}$ pasien ditemukan hasil radiodiagnosis berupa odontogenic keratocyst dan Impaksi gigi 48 horizontal kelas III tipe C. Pasien lalu melakukan rencana pengangkatan kista tersebut dan gigi Impaksi secara bersamaan sekaligus dilakukan konfimasi biopsi untuk melihat apakah terdapat sel keganasan. Hasil pemeriksaan biopsi dari dokter spesialis Patologi Anatomi (Gambar 4) mengkonfirmasi bahwa lesi tersebut adalah odontogenic keratocyst. Gambaran HPA tidak diberikan hanya hasil pemeriksaan biopsi. Pasien selanjutnya melakukan pengangkatan massa dan kontrol pada pasien dilakukan setelah pemasangan bar dengan menggunakan pemeriksaan panoramik (Gambar 5). 
Setelah dilakukan perawatan pembedahan pasien kembali untuk melakukan konsultasi bahwa pernah dilakukan pemeriksaan panoramik sebelumnya 2 tahun lalu tetapi karena tidak dilakukan pembacaan interpretasi panoramiknya sehingga lesi tersebut tidak diketahui. Hal ini terjadi karena pasien pada saat itu melakukan pemeriksaan panoramik untuk dilakukan perawatan pencabutan pada bagian gigi 36. Kontrol 2 minggu pasca pembedahan dilakukan dengan pemeriksan panoramik untuk konfirmasi hasil pembedahan (Gambar 4), kemudian pasien disarankan untuk pemeriksaan kontrol setelah 6 bulan untuk memastikan terjadinya rekurensi.

\section{DISCUSSION}

Odontogenic keratocyst dapat terjadi pada pria dan wanita dalam rentang usia dekade kedua dan ketiga ${ }^{9}$, Karwasra (2017) menyebutkan bahwa masih dapat terjadi pada dekade ketiga dan keempat ${ }^{15}$, namun tidak menutup kemungkinan bahwa dapat terjadi pada pasien diatas dekade keempat. Odontogenic keratocyst terkadang tidak menimbulkan gejala, namun pada kasus in terdapat keluhan gigi goyang pada regio 44-48 yang terjadi karena adaya tekanan dari kista. ${ }^{9}$ Penyebab terjadinya odontogenic keratocyst masih belum dapat dipastikan namun dapat diperkirakan terjadi akibat trauma, infeksi, odontogenic keratocyst keratocyst dapat terjadi pada seluruh bagian rahang, seperti antrum atau sinus maksilaris ${ }^{16,17}$ namun lebih umum terjadi pada bagian posterior dari badan mandibula dan ramus seperti pada pasien pada kasus ini. ${ }^{9}$

Keterlibatan gigi impaksi masih belum dapat dipastikan namun banyak kasus yang memperlihatkan adanya gigi impaksi yang terdapat pada odontogenic keratocyst. ${ }^{14,18}$ Hasil pemeriksaan lab PA dapat menegakkan diagnosis odontogenic keratocyst jika ditemukan kandungan keratin pada eksudat dan epitel skuamous tipis berkeratin dengan 4 hingga 10 lapisan, terdapat lapisan basal palisade yang jelas dari sel kolumnar atau kuboid, lapisan permukaan parakeratin bergelombang, dan biasanya terpisah antara epitel dan jaringan ikat. ${ }^{19}$

Pada pasien tersebut, tatalaksana yang dilakukan adalah tatalaksana agresif, yaitu dengan melakukan reseksi pada regio rahang yang terlibat sehingga dapat mengurangi rekurensi yang akan terjadi. ${ }^{20}$ Selain itu dapat pula dilakukan tatalaksana konservatif yaitu dengan cara enuklease dan/atau marsupialisasi. ${ }^{21}$ Tatalaksana lainnya yang dapat dilakukan adalah enuklease dengan kuretase kimiawi menggunakan larutan Carnoy (60\% ethanol, $30 \%$ chloroform, $10 \%$ asam asetik glasial, dan $1 \mathrm{gr}$ ferric chloride). ${ }^{22}$ Pengambilan gigi yang terlibat dapat dipertimbangkan karena dapat meningkatkan resiko rekurensi. ${ }^{21}$ Pada kasus ini, dilakukan pengangkatan gigi yang terlibat mulai dari gigi 45 48 seperti pada Gambar 4.

Odontogenic keratocyst dapat ditemukan pada pemeriksaan radiograf rutin dengan gambaran radiolusen, bentuk oval atau bulat, dan meluas di sepanjang badan mandibula, memiliki tepi halus dan jelas, terkadang memiliki gambaran yang terkortifikasi. $^{23}$ Tampilan CT terkadang menunjukkan adanya keratin yang terdeskuamasi yang berkumpul di pola nonhomogen pada cairan dengan kekentalan rendah didalam kavitas kista sehingga menghasilkan tampilan tumor heterogeny. ${ }^{24}$ Kebanyakan tumor dan kista odontogenik tidak menunjukkan tanda radiograf hingga mencapai ukuran tertentu, bahkan terkadang bersifat asimptomatik saat tahap progresif. ${ }^{25}$

Diagnosis banding dari odontogenic keratocyst antara lain adalah ameloblastoma, kista periodontal, kista radikular, kista dentigerous, dan odontogenic myxoma. ${ }^{9,13}$ Menurut Alves (2018) menyatakan bahwa pada ameloblastoma terdapat

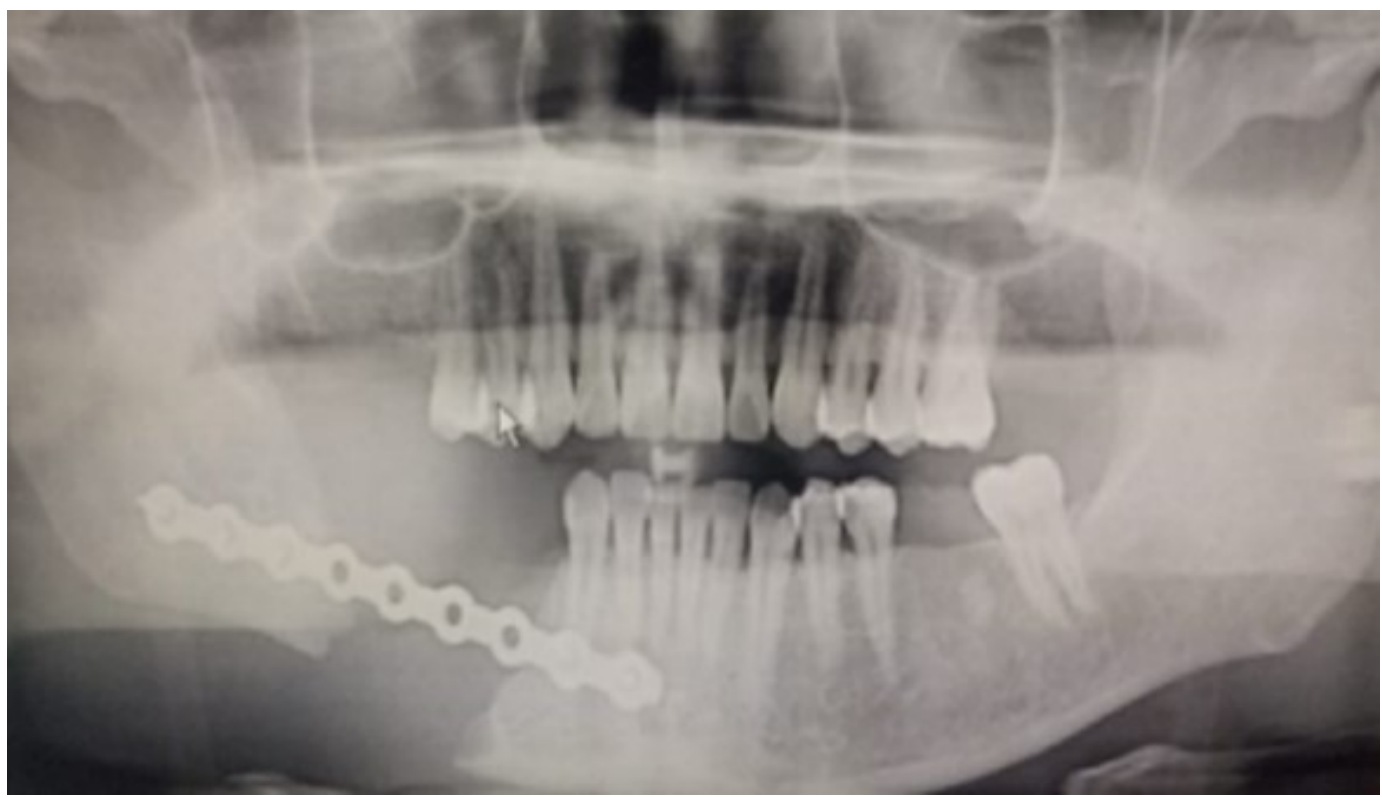

Gambar 5. Panoramik menujukkan kondisi rahang mandibula dextra 2 minggu pasca operasi 
ekspansi tulang kortikal mandibula sedangkan pada odontogenic keratocyst tidak ditemukan. Selain itu, pada odontogenic keratocyst ditemukan tampilan unilocular dengan septa sedangkan ameloblastoma menunjukkan gambaran multilocular. ${ }^{11}$ Odontogenic keratocyst lebih banyak muncul pada badan mandibula dibandingkan ameloblastoma serta ameloblastoma lebih sering mengakibatkan resorpsi akar dibandingkan odontogenic keratocyst. $^{26}$ Pada kista periodontal dapat dibedakan dengan odontogenic keratocyst berdasarkan perluasannya. Kista periodontal sangat menyerupai odontogenic keratocyst kecil sehingga apabila dibiarkan, odontogenic keratocyst memilik kecenderungan untuk meluas. Kista radicular umumnya terjadi pada gigi dengan pulpa non-vital, sedangkan odontogenic keratocyst dapat terjadi pada geligi yang masih vital. Kista dentigerous memiliki kecenderungan untuk meluas ke arah tulang dan mungkin terjadi resorpsi akar gigi, sedangkan pada Odontogenic keratocyst tidak memiliki perluasan ke arah tulang dan resorpsi akar gigi meskipun dengan dengan derajat yang lebih rendah dibandingkan kista dentigerous. ${ }^{9}$

\section{CONCLUSION}

Odontogenic keratocyst paling sering terjad pada posterior mandibula, unilocular jinak dan biasanya berasal dari sel dental lamina. Odontogenic keratocyst secara radiologi memiliki karakteristik berupa gambaran lesi radiolusensi yang meluas kadang hampir berbentuk scallop dengan batas kortikal yang jelas sesuai dengan hasil interpretasi dari CBCT. Pemeriksaan 3D CBCT dapat memberikan data dan ukuran dari bentuk lesi dan luas lesi sehingga sangat membantu untuk rencana perawatan pembedahan. Lesi ini ditemukan dar pemeriksaan CBCT dan pasien tidak merasakan adanya rasa sakit dan pembengkakan hanya merasakan gigi goyang. Odontogenic keratocyst dapat didiagnosa dengan baik menggunakan kombinasi pemeriksaan CBCT dan pemeriksaan histopatologi untuk menentukan tatalaksana paling efektif dan mencegah kumungkinan rekurensi.

\section{ACKNOWLEDGMENTS}

None.

\section{FOOTNOTES}

All authors have no potential conflict of interest to declare for this article. Informed consent was obtained from the patient for being included in this case report.

\section{REFERENCES}

1. Borghesi A, Nardi C, Giannitto C, Tironi A, Maroldi R, Di Bartolomeo $\mathrm{F}$, et al. Odontogenic keratocyst: imaging features of a benign lesion with an aggressive behaviour. Insights Imaging. 2018:9:883-97.

2. Antonoglou GN, Sándor GK, Koidou VP, Papageorgiou SN. Non -syndromic and syndromic keratocystic odontogenic tumors: Systematic review and meta-analysis of recurrences. J CranioMaxillofacial Surg. 2014;30:1-8.

3. Jaeger F, de Noronha MS, Silva MLV, Amaral MBF, Grossmann $S$ de $M C$, Horta MCR, et al. Prevalence profile of odontogenic cysts and tumors on Brazilian sample after the reclassification of odontogenic keratocyst. J Cranio-Maxillofacial Surg. 2017;45(2):267-70.

4. Kshirsagar R, Bhende R, Raut $P$, Mahajan V, Tapadiya V, Singh V. Odontogenic keratocyst: Developing a protocol for surgical intervention. Ann Maxillofac Surg. 2019;9:152-7.

5. Avril L, Lombardi $T$, Ailianou $A$, Burkhardt $K$, Varoquaux $A$ Scolozzi $P$, et al. Radiolucent lesions of the mandible: $A$ pattern-based approach to diagnosis. Vol. 5, Insights into Imaging. 2014. p. 85-101.

6. Mendes RA, Carvalho JFC, van der Waal I. Characterization and management of the keratocystic odontogenic tumor in relation to its histopathological and biological features. Oral Oncol. 2010;46(4):219-25.

7. Sekhar MC, Thabusum DA, Charitha M, Chandrasekhar G, Shalini M. A Review of the Odontogenic Keratocyst and Report of a Case. J Adv Med Med Res. 2019;29(8):1-7.

8. Kadam VD, Changule G, Gade LP, Choudhary SH. An interesting case of odontogenic keratocyst mimicking traumatic bone cyst. Int J Med Dent Case Reports. 2021;7:1-3.

9. Mallaya S, Lam E. White and Pharoah's Oral Radiology. White and Pharoah's Oral Radiology: Principles and Interpretation. 2018.

10. Byatnal A, Natarajan J, Narayanaswamy V, Radhakrishnan R. Orthokeratinized odontogenic cyst - critical appraisal of a distinct entity. Brazilian J Oral Sci. 2013;12(1):71-5.

11. Alves DBM, Tuji FM, Alves FA, Rocha AC, Dos Santos-Silva AR, Vargas PA, et al. Evaluation of mandibular odontogenic keratocyst and ameloblastoma by panoramic radiograph and computed tomography. Dentomaxillofacial Radiol. 2018;47 (7):1-7.

12. Okkesim A, Adışen MZ, Mısırlıŏglu M, Tekin U. Diagnosis and treatment of keratocystic odontogenic tumor mimicking a dentigerous cyst in panaromic radiography. TURKISH J Clin Lab. 2017;8(1):28-31.

13. Kitisubkanchana J, Reduwan NH, Poomsawat $S$, Pornprasertsuk-Damrongsri S, Wongchuensoontorn C. Odontogenic keratocyst and ameloblastoma: radiographic evaluation. Oral Radiol. 2021;37(1):55-65.

14. Mhaske SJ, Mulchandani R, Saawarn S, Mandale SS. Unusual Aggressive Presentation of Orthokeratinized Odontogenic Cyst -A Case Report with Systematic Review of Literature. Int J Contemp Med Res Int J Contemp Med Surg Radiol. 2017;2 (3):97-101.

15. Karwasra K, Choudhary D, Astekar M, Gandhi N. Clinicopathological study of Odontogenic Cysts -a retrospective study. RUHS J Heal Sci. 2017;2(1):29-32.

16. Gadicherla S, Kamath AT, Dhara BV, Smriti K. Keratocystic Odontogenic Tumor Involving Maxillary Antrum. Online J Heal Allied Sci. 2017;16(4):1-3.

17. Sheethal HS, Rao K, S UH, Chauhan K. Odontogenic keratocyst arising in the maxillary sinus: A rare case report. J oral Maxillofac Pathol. 2019;23:S74-7.

18. Boopathi D, Kumaran JV Subramanian S Vasudevan, Mariappan JD, Department. Conventional radiograph and cone? beam computed tomography in the evaluation of odontogenic cysts and tumors an analysis of seven cases. 2020;11:54-9.

19. Azevedo RS, Cabral MG, Santos TCRB Dos, De Oliveira AV, De Almeida OP, Pires FR. Histopathological features of keratocystic odontogenic tumor: A descriptive study of 177 cases from a Brazilian population. Int J Surg Pathol. 2012;20 (2):154-60.

20. Karaca C, Dere KA, Er N Aktas A, Tosun E, Köseoğlu OT, et al. Recurrence rate of odontogenic keratocyst treated by enucleation and peripheral ostectomy retrospective case series with up to 12 years of follow-up. Med Oral Patol Oral y Cir Bucal. 2018;23(4):e443-8.

21. Cunha JF, Gomes CC, De Mesquita RA, Andrade Goulart EM, De Castro WH, Gomez RS. Clinicopathologic features associated with recurrence of the odontogenic keratocyst: A cohort retrospective analysis. Oral Surg Oral Med Oral Pathol Oral Radiol. 2016;121(6):629-35.

22. Polak K, Jedrusik-Pawłowska M, Drozdzowska B, Morawiec T. Odontogenic keratocyst of the mandible: A case report and 
literature review. Dent Med Probl. 2019;56(4):433-6.

23. Whaites E, Cawson RA. Essentials of Dental Radiography and Radiology. 5th ed. Elsevier; 2013.

24. Cardoso LB, Lopes IA, Ikuta CRS, Capelozza ALA. Study Between Panoramic Radiography and Cone Beam-Computed Tomography in the Diagnosis of Ameloblastoma, Odontogenic Keratocyst, and Dentigerous Cyst. J Craniofac Surg. 2020;31 (6):1747-52.

25. Yang $\mathrm{H}$, Jo E, Kim HJ, Cha I, Jung Y-S, Nam W, et al. Deep Learning for Automated Detection of Cyst and Tumors of the Jaw in Panoramic Radiographs. J Clin Med. 2020;9(6):1839.

26. Liu Z, Liu J, Zhou Z, Zhang Q, Wu H, Zhai G, et al. Differential diagnosis of ameloblastoma and odontogenic keratocyst by machine learning of panoramic radiographs. Int J Comput Assist Radiol Surg. 2021;16(3):415-22. 